\title{
Research on the Risk Control Mechanism of Sino- Foreign Cooperative Schools of Higher Education Under Regular Epidemic Prevention and Control of COVID-19
}

\author{
Hao Wang ${ }^{1, *}$ Jinpeng Wang ${ }^{1}$ Jinyu Zhang ${ }^{1}$ Chunwen Ren $^{1}$ \\ ${ }^{1}$ Guangzhou College of South China University of Technology, Guangzhou, Guangdong 510800, China \\ *Corresponding author.Email:wanghao@gcu.edu.cn
}

\begin{abstract}
As an important pattern of internationalization, Sino-foreign cooperation in education is now on the fast track of development. With continuous expansion of education, the risk prevention and management in Sino-foreign cooperative universities has not formed a complete theoretical system yet. Combined the actual situation of Sinoforeign Cooperative universities under regular epidemic prevention and control of COVID 19 with relevant theories and methods about risk management of foreign universities, this research puts forward a theoretical system of Sino-foreign Cooperative universities' overall risk management and discusses about the importance of using this system in higher education.
\end{abstract}

Keywords: Regular epidemic prevention and control of COVID-19, Sino-foreign cooperative universities, Higher Education, Risk management.

\section{INTRODUCTION}

At present, the coronavirus is still raging around the world with a cumulative number of confirmed cases over 30 million. Many countries have not seen the turning point of this epidemic yet and the population movements have been severely hampered. Since the outbreak of this global epidemic, China-US relations have faced new challenges. Some Western countries, such as United States, have tightened their policies and Sino-foreign cooperation in running schools has been deeply affected. Based on the new changes in the international situation, putting forward the risk control mechanism under the regular epidemic prevention and control from the perspective of Sino-foreign cooperation in running schools is of great practical significance for accelerating and expanding the opening-up of education in the new era. Sino-foreign cooperation in running schools is an important way for the internationalization of education. Compared with general education, Sinoforeign cooperative education has a governance structure of mutual participation, so its particularity is obvious. If the risks caused by this particularity cannot be prevented and controlled effectively, it will have a negative impact on Sino-foreign cooperative education institutions and projects, even international cooperation.

As of August 2020, there are nearly 2,300 Sinoforeign cooperative education institutions and projects have been approved or established by authorities across our country. Among them, 90\% are cooperation in higher education and China-US cooperative higher education institutions and projects are up to 450 , accounting for one-fifth of the total number of Sino-foreign cooperative education institutions and projects. In terms of types, there are 32 China-US higher education cooperative institutions (of which 29 are not qualified as legal person and 3 are qualified as legal person). Since the 18th National Congress of the Communist Party of China, Sino-foreign cooperation in running schools has improved its quality and efficiency, also aimed at serving the overall situation and strengthening its capabilities. From entry approval to supervision and then to the exit mechanism are all improving day by day. The 
cooperative scholars' awareness of self-discipline, self-regulation, self-management and their capacity have gradually increased at the same time. All these factors indicate the wide coverage and high degree of attention of Sino-foreign cooperation in running schools. However, during the process of cooperation, part of the risks of cooperation also unceasingly appears. For example, the matching degree of educational resources of the Chinese and foreign partners in running schools is lack of improvements that require communication between this two parties. In the cooperation of education, the structure of disciplines, major direction and regional distribution still require both parties to make more adequate preparations to avoid risks. In the practice of Sino-foreign cooperation in higher education, there is currently no comprehensive risk control and management system yet.

\section{DEVELOPMENT OF RISK PREVENTION AND CONTROL IN UNIVERSITIES}

In 2001, "Comprehensive risk management strategies for higher education" [1] was published by The National Association of College and University Business Officers (NACUBO) and PricewaterhouseCoopers (PwC). It defines the meaning of risk and 20 driving factors of risk. Also it introduces some methods of risk management and control and how to apply them to school management. Meanwhile, the Higher Education Funding Council for England (HEFCE) also encouraged the introduction of risk management into universities in England and wrote a report about risk management [2]. It elaborated on the concept of risk management and some application cases, especially some risks that higher education institutions may face with. In 2003, the University Risk Management and Insurance Association (URMIA) [3] stated the benefits of implementing risk management strategies in universities and how to carry out the risk management. In 2004, Enterprise Risk Management Integrated Framework (ERM) [4], [5] was put forward and it was regarded as a milestone. This framework is widely used by listed companies and large enterprises all around the world at present and it provides the standard language and easy-operated rules of risk management. At the same time, this framework is also promoted to some NGOS, universities and hospital gradually. This ERM framework has three dimensions. They are target dimension, level dimension and factor dimension. These three dimensions are all connected. Level dimension is the main body of management, factor dimension is requirement and target dimension is the object of implementation.

In 2007, a report named "Meeting the Challenges of Enterprise Risk Management in Higher Education"[6] was published on an educational summit in United States. This report elaborated the implementation of ERM framework in the risk management of higher education and developed a higher-education-specific model, which is specific for the ERM framework of higher education. In the same year, the White Paper: ERM in Higher Education [7] was published. It makes a complete introduction about the methods and templates and reference information of implementation of ERM framework. Meanwhile, it also provides the cases of four universities, such as University of California and Pennsylvania State University, to share the implementation situation of ERM in these universities. In 2008, PwC discussed the methods of implementation of ERM framework [8] in higher education and put forward the parallel strategy, which combines ERM with present risk management system.

University of California (referred to as UC) was the earliest university all around the world that implemented risk management in 2004. Moreover, it developed the ERM Maturity Model [9] based on ERM model in 2009. The risk management of University of California received high praise from many institutions, including Standard \& Poor's. Preparation work of risk management of UC has three parts. The first step is to set up an expert panel, the second step is to establish rules and regulations and the third one is to make a plan accordingly. The third step, making a plan is based on the eight elements of ERM framework: targets, environment, identification of incident, risk assessment, control events, risk response, information communication and monitoring supervision. In formulating the specific steps of the plan, UC makes description of each element, including the overall goal, sub-goals, areas of focus, specific programs, desired effect, assessment methods, corresponding leadership and timetable.

\section{MAJOR RISKS OF SINO-FOREIGN COOPERATION OF HIGHER EDUCATION UNDER COVID-19}

As the prevention and control of COVID-19 becomes regular, Sino-foreign Cooperation in running school is faced with unprecedented challenge. Chinese Administrative department of 
education took action such as guiding those students who take part in Sino-foreign Cooperative projects to study online, allowing universities in China offer short-term exchange learning program and expanding the enrollment of Sino-foreign Cooperative programs. However, risk of students and teachers, risk of teaching and scientific research, risk of finance, risk of school management, risk of student management and risk of infrastructure and maintenance are remained serious.

\subsection{Risk of Reducing of Number of Student and Teachers' Quality}

With the outbreak of COVID-19, the uncertainty of the enrollment number of Sinoforeign cooperative school of higher education increased. The attractiveness of foreign highquality educational resources, going overseas for further study after graduation, and other advantages has reduced. Students and their parents' motivation to apply for Sino-foreign cooperative school of higher education project has weakened. Thus, Sinoforeign cooperative school of higher education enrollment is facing great pressure.

\subsection{Risk of Student Management}

Under the influence of COVID-19, students who currently study abroad are facing many problems, such as infections of COVID-19, visa expiration, courses interruption, financial losses, emotional anxiety, cancellation of flight and so on. These are all resulting in the difficulties of student management and psychological guidance.

\subsection{Risk of Teaching and Scientific Research}

Since 26 March, 2020, The Ministry of Foreign Affairs and the National Immigration Administration issued an announcement that suspends foreigners with current valid visa and residence permit to enter China from 28 March, 2020. This announcement led to the situation that foreign teachers couldn't come to China for face to face teaching but only online teaching. However, because of the relevant policy of Sino-foreign cooperation in higher education, some of the highquality teaching education resources haven't been introduced into China yet. Therefore, the outbreak also resulted in the situation that most Sino-foreign cooperative schools of higher education did not have enough time to prepare both the hardware and the software for online teaching. On the other hand, because of the tension between China and United States and the misleading information from some western media, some Sino-foreign cooperative teaching or scientific research programs in school of higher education are under great influence and cannot have sustainable development.

\subsection{Risk of Finance}

If students who are studying in Sino-foreign cooperative programs keep paying tuition fees under this condition, they might have a huge psychological gap because they can only have online courses. They will think it is unworthy. This may lead to some unstable factors and need to be handled carefully. Apparently, the compensation of tuition fees of Sino-foreign cooperative school of higher education institutions is the problem that needs to deal with.

\subsection{Risk of Infrastructure and Maintenance}

In order to prevent and control COVID-19, according to Chinese government's requirements, Sino-foreign cooperative schools of higher education should set up and improve the public health infrastructure of schools, stock up disinfectants, masks, gloves and other antiepidemic materials. Meanwhile, schools also need to set up temporary quarantine areas for teachers, students and other staff who has symptoms. Also schools need to arrange specific people to be responsible for the management of school sanitation facilities, health security, supervision and implementation.

\subsection{Risk of Academic and Degree Certification}

The Sino-foreign cooperative universities or Chinese schools, which have carried out "doublecampus" cooperative school-running projects, have already taken those students who already got offer from foreign schools for the time being. But there are still some technical obstacles to lessons and credit transfer. Some actions about academic and degree certification, the length of stay in foreign countries and the plan of courses have been taken, but relevant policies still need to be strengthened.

From the present situation, it is unrealistic to put out the epidemic in a short time. We should think about how to establish an effective communication 
mechanism, information sharing mechanism and risk prevention and control mechanism of Sinoforeign cooperative schools of higher education to maximum satisfy the foreign students and international students' demand for professional information resources and other aspects of demand for study. On the one hand, the epidemic had a great impact on Sino-foreign cooperation in running schools and international educational exchanges, such as the closure of country borders, the suspension of exchange program between Chinese and foreign universities and the restriction of international exchanges between teachers and students. Moreover, universities' further expansion of overseas partners, deepening international cooperation and promoting the establishment of Sino-foreign cooperation in running schools are all approaching a bottleneck.

On the other hand, the epidemic has had a profound impact on the international pattern and the evolution of the international order. It has caused a heavy blow to the world economy and major adjustments have occurred in globalization. The trend of anti-globalization in Europe and United States is surging in many fields. Also the relations between China and some Western countries that are rich in higher education resources tend to be tense. Some foreign colleges and universities have set more restrictions on the professional fields of Sinoforeign cooperation in running schools of higher education, the strategic risk of Sino-foreign cooperation is facing many challenges.

\section{THOUGHTS ON RISK PREVENTION OF SINO-FOREIGN COOPERATION OF HIGHER EDUCATION UNDER REGULAR EPIDEMIC PREVENTION AND CONTROL OF COVID-19}

With regular epidemic prevention and control of COVID-19, the risk prevention and control require effective integrated with both sides of Sino-foreign cooperation, also with great support of government and society. China started up late in research and application of risk management. We did published some guidelines or documents about risk management since 2006. For example, State-owned Assets Supervision and Administration Commission (SASAC) published "The central enterprise comprehensive risk management guidelines" in 2006, but we are still at an early stage of development and application when compared to that in Europe or United States. Professor Hongxing Fang, who is from Dongbei University of Finance and Economics, translated the ERM template and therefore laid the foundation for related studies from then on.

Relevant government departments should guide Sino-foreign cooperative universities to formulate and introduce risk prevention and control programs as soon as possible, also need to conduct high-level consultations on issues such as students' placement needs, students' returning back to country, foreign teachers' coming to China, curriculum docking, mutual recognition of credits and academic degree certification, campus management, teaching order, length of study, tuition fees, cost compensation and so on. For example, Shanghai New York University, Kunshan Duke University and Wenzhou Kern University, these schools are all familiar with the overall operation mode of American universities and locate in major cities in the Yangtze River Delta region with high level of economic and social development. They also have high degree of opening up to the outside world. They can lead to build a mechanism and platform for risk prevention and control in Sino-US cooperative schools of higher education and provide guidance for risk prevention and management.

The risk prevention and control and management of Sino-foreign cooperation in running schools of higher education involves both Chinese and foreign countries. It is professional and related to policy and political. The relevant government departments involved in Sino-foreign cooperation in running schools of higher education should work out risk prevention and control plans as soon as possible to avoid potential frictions and disputes in teaching management or financial arrangements, and ensure the safety of education and teaching.

In accordance with the principle of regional management for epidemic prevention and control, risk prevention and control should be incorporated into the overall working mechanism of local Party committees and the government's epidemic prevention and control. In accordance with the work idea of "External anti-input, internal antirebound", comprehensive and strict prevention and control measures should be taken to ensure the health and safety of teachers, students and social stability in view of the different characteristics of returning students, foreign teachers and students in China. 
As a special arrangement for Chinese students who already got offer from foreign universities, the Sino-foreign cooperative universities take these student in and carry out relevant education and teaching work for them. This arrangement can not only meet the needs of our students studying abroad and protect their legitimate rights and interests, but also solve practical difficulties for foreign cooperative universities, which is conducive to release positive signals of openness, tolerance and friendly cooperation, also enhance trust and cooperation between countries.

\section{RISK ASSESSMENT OF SINO- FOREIGN COOPERATION OF HIGHER EDUCATION UNDER REGULAR EPIDEMIC PREVENTION AND CONTROL}

By combing through the risk cases of some Sino-foreign cooperative schools of higher education in China and comparing the 8 risk classifications of University of California, we puts forward 8 main risks of Sino-foreign cooperation with regular epidemic prevention and control. They are risk of law and policy, risk of teaching and scientific research, risk of students' enrolment and teachers' quality, risk of student management, risk of finance, risk of campus life, risk of cooperation and risk of environment.

\subsection{Risk of Law and Policy}

According to the Regulations of the People's Republic of China on Sino-foreign Cooperation in Running Schools issued by the State Council, Chinese-foreign cooperative schools are mainly in China and the major enrollment are Chinese citizens. The Chinese side must make a lot of investment in people and property in all aspects to ensure the smooth implementation of the project. However, Sino-foreign cooperation in running schools is a very policy-oriented activity and influence by a variety of policies, such as Sinoforeign cooperation in running schools regulations, foreign exchange management policies, tax and fee policies, foreign teachers introduction policy, degree certification policy, the coronavirus prevention and control regulations policy compilation and legal advice guidelines. At the same time, it is also a cross-border, cross-cultural mode of running a school involving multiple stakeholders, so the legal and policy risks are particularly prominent in the specific course of running a school.

\subsection{Risk of Teaching and Scientific Research}

If the syllabus, training program and assessment methods of Sino-foreign cooperative schools are not fully discussed and linked, it is difficult to form a scientific, unique and integrated curriculum system of the project. The actual situation is often two sides' teaching and scientific research are independent. The low degree of integration for Chinese and foreign teachers and two sets of remuneration and evaluation system and other comprehensive factors, making many projects of teaching, scientific research lack of systematic and continuity.

\subsection{Risk of students' Enrolment and Teachers' Quality}

According to the Ministry of Education, a foreign university in China carried out chain-store replication teaching mode and coupled with some agents to participate in packaging and even the preparation of Chinese-foreign cooperation in running schools, major settings, cooperation models and other low-level duplication, homogenization of the competition phenomenon is becoming increasingly prominent. In the recruitment process, by reducing the batch transfer voluntary and individual code of low-quality students, this makes the quality of enrollment is uneven; The mobility of foreign teachers is high and the professionalism is lacking, which is even worse for students with weak academic level and poor autonomy ability.

\subsection{Risk of Student Management}

The academic and cultural differences between Chinese universities' "strictly in and out" and foreign universities' "wide-out" admission and degree awarding; the high fees charged by Chinese and foreign cooperative school-running projects; the high expectations of Sino-foreign cooperative projects from society, parents and students and coupled with the high-intensity curriculum system with foreign language as the main orientation; all the above factors have caused great obstacles to student management.

\subsection{Risk of Finance}

The relatively high running costs and expenses of international projects, the exchange rate fluctuations in the process of capital transfer between partners, poor management in the financial 
system, management system, clearing system and accountability system of special funds and assets of the project, the dysfunctional other risk prevention and control systems, all these factors make the sustainability of Sino-foreign cooperative schools of higher education unsound. Especially during the epidemic, the enrollment number has decreased, and the increase in the expenditure on epidemic prevention and control made the financial risk more prominent.

\subsection{Risk in Campus (Including Cultural Difference Risk, Internal Management Risk, Academic Degree Certification Risk, Etc.)}

As a form of running a school that involving the two schools, investors, school staff, project students and parents, the Chinese and foreign parties have great differences in cultural traditions, educational concepts, educational objectives, educational methods and quality systems, therefore it formed some risks rarely seen in the general higher education system. The epidemic has brought unprecedented pressure to campus management, we should take careful preventive and control measures, strengthen campus management, improve emergency plans, and further improve security.

In addition, lack of school experience, lack of professional management, management team's cultural differences and other factors all can cause project management failure, or even fail to pass the Ministry of Education review and evaluation. These will lead to project termination and other risks. The education administrative department has a variety of explanations for academic degree certification, including academic qualification, degree certification, study abroad certification, etc., under the premise that students and parents are vague about these concepts, some Chinese and foreign cooperative school-running institutions or projects use "cooperative school", "joint training" and other special terms that make students and parents are very confused. Even more, some students were induced to apply for the project without the approval of the education administrative department. Under this condition, when students graduate, their foreign degree cannot be certified.

Different institutional frictions, conflicts of cooperation objectives between Chinese and foreign universities, training models that do not adapt to social and economic development, and multi-interests can not be guaranteed at the same time are the main reasons. At the same time, the differences between the two sides in the strategic development direction of higher education are caused by different factors: the foreign party cooperate with many Chinese institutions at the same time, different cooperation contracts between different cooperative institutions are difficult to restrain each other, lack of a strong restraint mechanism during the implementation of contract, the conflict between actual implementation of the contract and rules and regulations, etc., are important factors driven by risk.

Based on the causes of risk and the risk assessment matrix of higher education, the risk control structure of higher education and the main steps of budget assessment, the risk management framework of higher education ("Figure 1") is established.
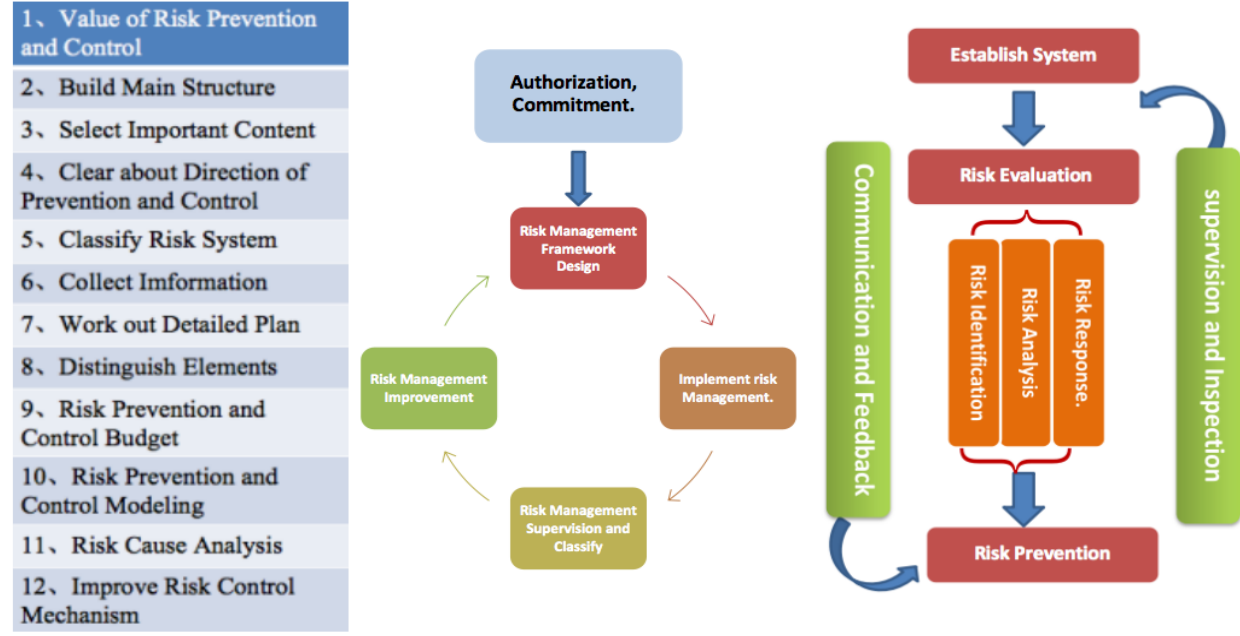

Figure 1 Framework of higher education risk management. 
- Higher education risk assessment matrix is for identifying, assessing, monitoring and responding to different types of risks.

- For the higher education risk control structure assessment system, because of the evaluation of the effectiveness of the current risk control, we first define the grade and weight, followed by the assessment of risk. The risk assessment mainly focuses on the risk control assessment, especially the need to predict the impact of control failure, what is the impact? How big is the impact?

- Risk management budget assessment is used to assess the cost of each risk management and the potential benefits of reducing risk or gain, and then achieve the best risk management model through a more reasonable budget distribution.

\section{CONCLUSION}

To sum up, in addition to the external supervision in the education administrative department with the regular epidemic prevention and control of COVID-19, it is necessary to strengthen the self-supervision of the main body schools, so as to form a risk prevention and control mechanism of the organic combination of main body, government, society and so on. At the same time, it will be beneficial for risk managers to identify and analyze existing and potential risks in depth and comprehensively, so that Chinese and foreign school of higher education can effectively avoid, control or manage all risks. Only under this condition we can realize the steady and healthy development of Sino-foreign cooperation in higher education.

\section{AUTHORS' CONTRIBUTIONS}

This article is completed by Hao Wang, Jinpeng Wang, Jinyu Zhang, and Chunwen Ren. Hao Wang is responsible for the direction, structure design and revision of the paper; Jinpeng Wang is responsible for the writing and modeling of the paper; Jinyu Zhang is responsible for the investigation and translation of foreign language literature; Chunwen Ren is responsible for data sorting and data analysis.

\section{REFERENCES}

[1] Cassidy, D., et al., Developing a strategy to manage enterprisewide risk in higher education. Washington, DC: NACUBO and Pricewaterhouse Coopers LLP, 2001.
[2] Coopers, P., Risk management: A guide to good practice for higher education institutions. 2001.

[3] Jane Dickerson, P.F.a.L.F., Enterprise Risk Management: A Fundamental Practice for Higher Education. 2003, University Risk Management and Insurance Association.

[4] Commission, C.o.S.O.o.t.T., Enterprise Risk Management - Integrated Framework: Application techniques. 2004: COSO.

[5] Commission, C.o.S.O.o.t.T., Enterprise Risk Management - Integrated Framework: Executive Summary Framework. 2004: COSO.

[6] Mattie, J., Meeting the Challenges of Enterprise Risk Management in Higher Education. National Association of College and University Business Officers (NJ1), 2007.

[7] Morris, V., URMIA White Paper: ERM in Higher Education. 2007.

[8] Mattie, J. and D. Cassidy, Achieving goals, protecting reputation: Enterprise Risk Management for Educational Institutions. 2008.

[9] California, E.P.U.o., University of California Enterprise Risk Management Report 2012. 